\title{
Der Kern unseres Berufs
}

\section{Michel Matter}

Dr. med., Vizepräsident der FMH, Departementsverantwortlicher Dienstleistungen und Berufsentwicklung

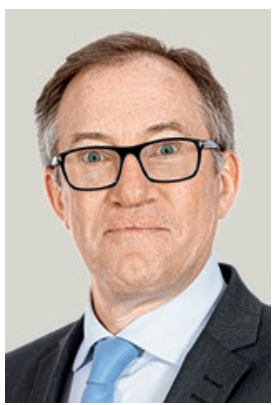

Die Medizin muss im Dienste aller stehen. Allerdings gibt es in unserem Alltag Ungleichheiten. Damit sich diese Ungleichheiten nicht in unser tägliches Handeln einschleichen, müssen wir immer auf der Hut sein. Der Tod von George Floyd am 25. Mai 2020 in Minneapolis und die darauffolgenden Gefühls- und Wutausbrüche zeigen einmal mehr, wie wichtig der Kampf gegen jede Art der Rassendiskriminierung ist. So zeigte auch der Tod der amerikanischen Bürgerrechtsikone John Lewis im Alter von 80 Jahren, glühender Verfechter der Gewaltlosigkeit und Mitglied des Repräsentantenhauses, auf, wie notwendig und aktuell dieser Kampf gegen Vorurteile ist.

\section{Diese Verpflichtung unterstreicht die Be-} deutung einer diskriminierungsfreien Gleichbehandlung im Rahmen unserer Tätigkeit.

Ebenso aktuell ist der Kampf gegen die Ungleichbehandlung der Geschlechter. Die angesehene französische Rechtsanwältin und Frauenrechtlerin Gisèle Halimi meinte dazu: «Wann werden die Frauen begreifen, dass sie gemeinsam ungeheuer stark sind? Einzeln sind sie verletzlich. Gemeinsam sind sie eine unglaubliche Kraft.» Fragen von Ungleichheit und Sexismus auf institutioneller Ebene werden von einer neuen Generation von Pflegekräften immer häufiger thematisiert. Sie machen den Mund auf und sprechen Totgeschwiegenes an. Diese neue Redefreiheit berührt alle Bereiche unserer Gesellschaft, sowohl im Positiven als auch in all ihren Ausuferungen. Und immer stärker kommt sie auch in der Lehre zum Tragen.

Die Fakultät für Biologie und Medizin der Universität Lausanne bietet derzeit einen Kurs zum Thema Rassismus bei der medizinischen Arbeit an, wie Sylvie Logean am 28. Juli in der Tageszeitung Le Temps schreibt. Der Kurs thematisiert alle Facetten des Rassismus im Gesundheitssystem. Wir alle kennen die Genfer Deklaration, welche die Ärzteschaft zur Einhaltung bestimmter und doch eigentlich selbstverständlich erscheinender Regeln verpflichtet, die das Funda- ment unseres Berufes sind. Diese Verpflichtung unterstreicht die Bedeutung einer diskriminierungsfreien Gleichbehandlung im Rahmen unserer Tätigkeit. Patrick Bodenmann, Leiter des Bereichs Vulnerable Gruppen und soziale Medizin von Unisanté Lausanne, betont: «Das Pflegepersonal ist nicht gegen Vorurteile gefeit.» Es gelte, kleinste Formen der Aggression anzugehen, die zum «schleichenden Verlust des Wohlbefindens und der Widerstandsfähigkeit der Betroffenen» führen können, so Bodenmann.

Für alle da sein, seine Nächsten pflegen, alle gleich behandeln; dies ist die gigantische Herausforderung der COVID-19-Krise: Wie kann man allen Bürgerinnen und Bürgern Chancengleichheit, Zugang zu Spitälern, Intensivstationen und Intermediärpflege gewähren? Ungleichbehandlungen bei der Versorgung stellen eine Gefahr dar. Ein perfektes Beispiel hierfür ist das angekündigte und gefürchtete Globalbudget. Es lässt einen verschieden raschen Zugang zur medizinischen Versorgung $\mathrm{zu}$, bei der einige Privilegierte sofortige Behandlungen erhalten, während andere auf einen Termin für die Behandlung warten müssen.

\section{Die Gefahr liegt in der Ungleichbehandlung bei} der Versorgung. Ein perfektes Beispiel hierfür ist das angekündigte und gefürchtete Globalbudget.

Gegen diese Rationierung der Versorgung werden wir uns auflehnen, denn für alle da zu sein darf nicht zur Herausforderung werden. Erwägungen von Alter, Krankheit oder Behinderung, Glaube, ethnischer Herkunft, Geschlecht, Staatsangehörigkeit, politischer Zugehörigkeit, Rasse, sexueller Orientierung, sozialer Stellung oder jeglichen anderen Faktoren dürfen nicht zwischen die Pflichten der Ärztinnen sowie Ärzte und den Patientinnen und Patienten treten.

Wir müssen die Chancengleichheit bei der Behandlung gewährleisten und sozioökonomische Diskriminierung bekämpfen. Darin liegt der Kern unseres Berufs, der gelehrt, geteilt, wertgeschätzt und geschützt werden muss. 